PREPARED FOR THE U.S. DEPARTMENT OF ENERGY, UNDER CONTRACT DE-AC02-76CH03073

PPPL-3660

PPPL-3660

UC-70

Challenges for Plasma Diagnostic in a Next Step Device (FIRE)

by

Kenneth M. Young

January 2002

NM|

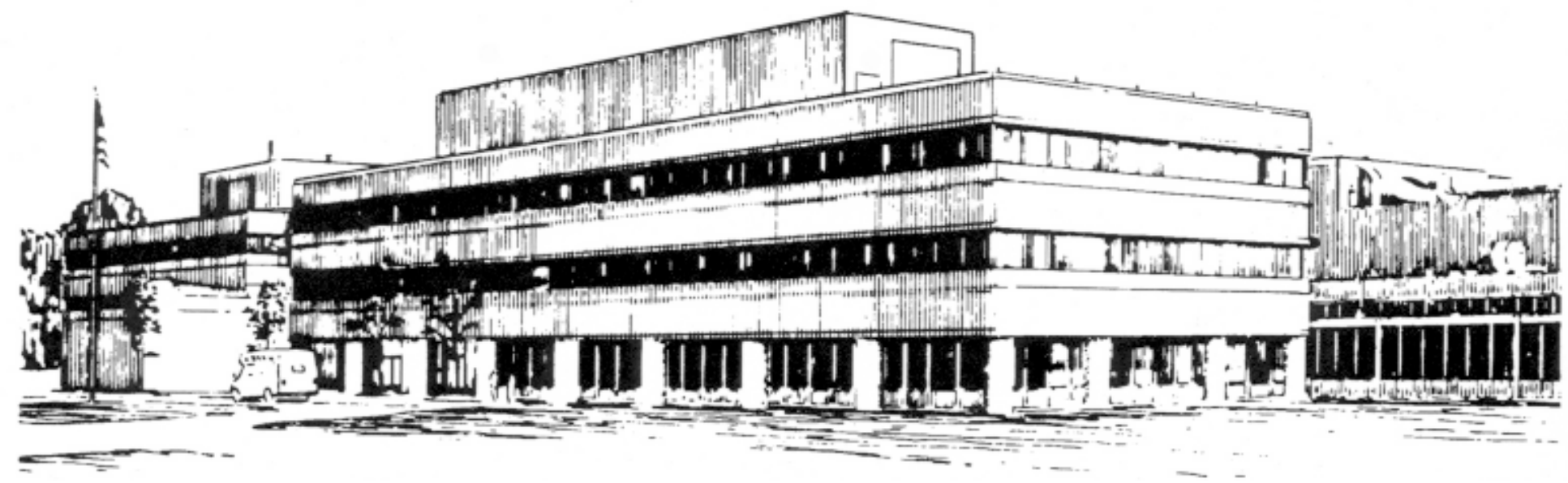

PRINCETON PLASMA PHYSICS LABORATORY PRINCETON UNIVERSITY, PRINCETON, NEW JERSEY 


\section{PPPL Reports Disclaimer}

This report was prepared as an account of work sponsored by an agency of the United States Government. Neither the United States Government nor any agency thereof, nor any of their employees, makes any warranty, express or implied, or assumes any legal liability or responsibility for the accuracy, completeness, or usefulness of any information, apparatus, product, or process disclosed, or represents that its use would not infringe privately owned rights. Reference herein to any specific commercial product, process, or service by trade name, trademark, manufacturer, or otherwise, does not necessarily constitute or imply its endorsement, recommendation, or favoring by the United States Government or any agency thereof. The views and opinions of authors expressed herein do not necessarily state or reflect those of the United States Government or any agency thereof.

\section{Availability}

This report is posted on the U.S. Department of Energy's Princeton Plasma Physics Laboratory Publications and Reports web site in Fiscal Year 2002. The home page for PPPL Reports and Publications is: http://www.pppl.gov/pub_report/

DOE and DOE Contractors can obtain copies of this report from:

U.S. Department of Energy

Office of Scientific and Technical Information

DOE Technical Information Services (DTIS)

P.O. Box 62

Oak Ridge, TN 37831

Telephone: (865) 576-8401

Fax: (865) 576-5728

Email: reports@adonis.osti.gov

This report is available to the general public from:

National Technical Information Service

U.S. Department of Commerce

5285 Port Royal Road

Springfield, VA 22161

Telephone: 1-800-553-6847 or

(703) 605-6000

Fax: (703) 321-8547

Internet: http://www.ntis.gov/ordering.htm 


\title{
Challenges for Plasma Diagnostics in a Next Step Device (FIRE)
}

\author{
Kenneth M. Young, Princeton Plasma Physics Laboratory, P.O. Box 451, Princeton, NJ, 08543
}

\begin{abstract}
The physics program of any next step tokamak such as FIRE sets demands for plasma measurement which are at least as comprehensive as on present tokamaks, with the additional capabilities needed for control of the plasma and for understanding the effects of the alpha-particles. The diagnostic instrumentation must be able to provide the fine spatial and temporal resolution required for the advanced tokamak plasma scenarios. It must also be able to overcome the effects of neutron- and gamma-induced electrical noise in ceramic components or detectors, and fluorescence and absorption in optical components. There are practical engineering issues of minimizing radiation streaming while providing essential diagnostic access to the plasma. Many diagnostics will require components at or close to the first wall, e.g. ceramics and MI cable for magnetic diagnostics and mirrors for optical diagnostics; these components must be mounted to operate, and survive, in fluxes which require special material selection. A better set of diagnostics of alpha-particles than that available for TFTR is essential; it must be qualified well before moving into $D$-T experiments. A start has been made to assessing the potential implementation of key diagnostics for the FIRE device. The present status is described.
\end{abstract}

\section{INTRODUCTION}

$\mathrm{T}$ HE success of any new next step burning plasma device will depend on the ability to control and understand the plasma behavior and to provide a sound basis for the design of a possible fusion reactor. This ability is crucially dependent on the measurement capability of a wide range of plasma diagnostics, whose measurements will be fed immediately back into controlling the plasma or very quickly into analysis codes. The measurement capability must enable the physics mission of the device [1] to be met, which will require, at least, the same quality of data as in the best present-day devices [2] [3], and new information about the alpha-particles, the new heating source. Very high quality, and reliable, information on many plasma parameters, e.g. the electron density and temperature profiles, will be necessary to permit operation in advanced tokamak modes. But a notable new aspect is that these measurements must be made in a very harsh radiation environment.

Three major physics aspects must be explored to move forward from our present understanding. a) Burning plasma physics where the new regime of fusion-dominated plasmas must be explored and understood; b) Advanced toroidal physics, coupled with the alpha-particle heating, to allow progress toward relatively small reactors, and c) Boundary physics where the coupling between the core and edge plasmas when very high heat fluxes must be withstood by the material walls.

The measurement requirements of ITER have been

Work supported by DOE Contract \#DE-AC02-76CHO 3073 considered carefully and considerable effort has been spent on evaluating diagnostics for carrying out these measurements and, in many cases, making detailed designs of the diagnostic interfaces with the tokamak and its shielding [4], [5]. Table 1 shows proposed specifications for a few of the fifty or so measurements necessary for FIRE - these numbers are relatively similar to those proposed for ITER. Because of its smaller size than ITER, and the planned higher fields and densities, it may be harder to meet the requirements for FIRE. A large number of these measurements will be in aspects of control; these are anticipated to be control of plasma shape and position, control of kinetic plasma profiles in the core, control of the current profile and rotation, control of fueling and optimizing the plasma interaction with the divertor.

Having established the measurement requirements, the individual diagnostic instruments which might be used to make the measurements have to be considered. Often a number of different techniques must be used for one measurement because of differences in spatial resolution or time resolution, or in the dynamic range over which they can operate. Also, in exploring new plasmas, with new regimes of plasma parameters, it is important to have comparison capability between two techniques dependent on different physics. In a paper of this length it is not possible to list the complete set of diagnostics being considered. For example, measurement of electron density might be measured by laser Thomson scattering or by interferometry or polarimetry of waves in the far infra-red in the core, by mm-wave reflectometry at the transport boundary near the edge, by probes in the scrape-off region and close to the divertor plates, and by Thomson scattering or interferometry near the X-point and along the plasma leg between the $\mathrm{X}$-point and the divertor strike point.

Section II is a short introduction to the impact of radiation on diagnostics. Section III addresses some issues of integration of diagnostics with the vacuum vessel, and its shielding and internal hardware. Section IV provides a short introduction to the status of alpha-particle diagnostic techniques, whose improvement is a major need in the Research and Development (R\&D) needs described in section V.

Descriptions of the FIRE mission and device can be found in reference [1] with details of the first-wall and plasma facing components described in reference [6].

\section{RADIATION IMPACT ON DIAGNOSTICS}

The design of diagnostic systems on a next step device like FIRE must be incorporated into the design of the tokamak itself. Apart from the obvious need to close the vacuum 
TABLE 1

Sample Measurement Requirements Proposed for FIRE

\begin{tabular}{|c|c|c|c|c|}
\hline PARAMETER & PARAMETER RANGE & $\begin{array}{l}\text { SPATIAL } \\
\text { RESOLUTION }\end{array}$ & $\begin{array}{l}\text { TIME } \\
\text { RESOLUTION }\end{array}$ & ACCURACY \\
\hline Plasma current & $0.1-8.0 \mathrm{MA}$ & Not applicable & $1 \mathrm{~ms}$ & $1 \%\left(\mathrm{I}_{\mathrm{p}}>1 \mathrm{MA}\right)$ \\
\hline Total neutron flux & $1 \times 10^{14}-2 \times 10^{20} \mathrm{~ns}^{-1}$ & Integral & $1 \mathrm{~ms}$ & $10 \%$ \\
\hline $\begin{array}{l}\text { Neutron \& } \\
\text { a-particle source }\end{array}$ & $1 \times 10^{14}-4 \times 10^{18} \mathrm{~ns}^{-1} \mathrm{~m}^{-3}$ & $\mathrm{a} / 10$ & $1 \mathrm{~ms}$ & $10 \%$ \\
\hline $\begin{array}{l}\text { Divertor surface } \\
\text { temperature }\end{array}$ & $200-2500^{\circ} \mathrm{C}$ & $1 \mathrm{~cm}$ & $2 \mathrm{~ms}$ & $10 \%$ \\
\hline $\begin{array}{l}\text { Core electron } \\
\text { temperature }\end{array}$ & $0.5-30 \mathrm{keV}$ & $\mathrm{a} / 30$ & $10 \mathrm{~ms}$ & $10 \%$ \\
\hline Edge electron density & $(0.05-10) \times 10^{20} \mathrm{~m}^{-3}$ & $0.5 \mathrm{~cm}$ & $10 \mathrm{~ms}$ & $5 \%$ \\
\hline $\begin{array}{l}\text { Radiation profile in } \\
\text { main plasma }\end{array}$ & $0.01-1 \mathrm{MW} \mathrm{m}^{-3}$ & $\mathrm{a} / 15$ & $10 \mathrm{~ms}$ & $20 \%$ \\
\hline $\begin{array}{l}\text { Radiation profile in } \\
\text { divertor }\end{array}$ & $\leq 100 \mathrm{MW} \mathrm{m}^{-3}$ & $5 \mathrm{~cm}$ & $10 \mathrm{~ms}$ & $30 \%$ \\
\hline
\end{tabular}

boundary with windows and electrical feedthroughs, diagnostics need clear lines of sight through shielding. Magnetic loops must be placed close to the plasma. To prevent streaming of the radiation through the apertures forming the sightlines, labyrinthine paths with mirrors are required. In some cases, such as for $14 \mathrm{MeV}$ neutrons to be measured to provide plasma measurement, straight-through apertures must be made as small as possible.

Table 2 shows some of the radiation levels in FIRE which are most applicable to diagnostics [7]. Usually the prompt flux levels will be most significant because the noise effects on signals are much more important than lifetime damage effects for FIRE. The lifetime dose levels are calculated for the full 5 TJ DT and 0.5TJ DD neutron emission within its plan. Readily damaged components such as photodiodes and viton will only be used in well-shielded locations.

The magnetic diagnostics, mounted close to the first wall, are most prone to radiation impact. For the flux levels at

TABLE 2

Radiation Environment at some FIRE Locations

\begin{tabular}{|c|c|c|c|}
\hline 200 MW DT Pulses & $\begin{array}{c}\text { Total Neutron } \\
\text { Flux } \\
\left(\mathrm{n} / \mathrm{cm}^{2} \mathrm{~s}\right)\end{array}$ & $\begin{array}{c}\text { Si -Dose } \\
\text { Rate } \\
(\mathrm{Gy} / \mathrm{s})\end{array}$ & $\begin{array}{c}\text { Total } \\
\text { Cumulative } \\
\text { Lifetime Dose } \\
\text { (Gy) }\end{array}$ \\
\hline $\begin{array}{l}\text { First Wall } \\
\text { (Inboard Midplane) }\end{array}$ & $1.54 \times 10^{15}$ & $1.17 \times 10^{4}$ & $3.09 \times 10^{8}$ \\
\hline $\begin{array}{l}\text { Behind Tiles } \\
\text { (Inboard Midplane) }\end{array}$ & $1.26 \times 10^{15}$ & $7.72 \times 10^{3}$ & $2.08 \times 10^{8}$ \\
\hline $\begin{array}{l}\text { Behind TF Coils } \\
\text { (Outboard } \\
\text { Midplane) }\end{array}$ & $9.52 \times 10^{8}$ & $1.2 \times 10^{-3}$ & 31.1 \\
\hline $\begin{array}{l}\text { Behind } 1.1 \mathrm{~m} \text { Port } \\
\text { Plug (Outboard } \\
\text { Midplane) }\end{array}$ & $1.01 \times 10^{8}$ & $6 \times 10^{-4}$ & 15.1 \\
\hline $\begin{array}{l}\text { Behind TF Coils at } \\
\text { Top/Bottom }\end{array}$ & $2.50 \times 10^{10}$ & $6.2 \times 10^{-2}$ & $1.63 \times 10^{3}$ \\
\hline
\end{tabular}

the first wall, radiation induced conductivity (RIC) increases the conductivity by over seven orders of magnitude in alumina ceramics. Careful selection of the insulator material will be necessary to maintain the signal integrity. Voltages can occur in the MI (mineral-insulated) cables used to transmit induced voltages from the coils to the vacuum feedthroughs, a problem which is being extensively investigated for ITER [8]. Long-term degradation effects are not likely to be serious, but it may be necessary to take precautions in design to limit the effect of nuclear heating during the pulse.

Radiation also intrudes on measurement quality through its effects in optical components. These are usually most manifest in fiber-optics because of their extended length so that transient absorption and luminescence can be significant for the low-light-level signals common to plasma diagnostics for either imaging or spectroscopic purposes. These effects were already apparent in TFTR where, in addition, studies were carried out directly on fibers [9]. An example is shown in fig. 1 where shielded quartz fibers run close to the outside wall of the TFTR vacuum vessel before turning away toward the detector area [10]. The flux levels close to the vessel are comparable to those expected at FIRE outside the shield plugs. The picture shows the imaged picture of the alpha-particles hitting a scintillating phosphor in a detector at the edge of the plasma. The detector is imaged onto a fiber bundle just outside the vacuum window. The peaked signal is that from the alpha-particles, while the pedestal is that caused in the fibers by the D-T neutrons and scattered gammas. For other spectroscopic diagnostics, a complex corrective set of dummy fibers to allow quantification of the induced absorption, as well as of the luminescence, were used [9]. Such systems will be required for FIRE, although new fibers with low-OH and fluorine additions are under study within the ITER research program [8]. Even with new developments it is very unlikely that the fibers will be able to give good quality data in much higher fluxes so that reflecting optics will be necessary to get light signals out to a reasonably low-level flux region. For the penetrations, difficult compromises between light throughput and streaming will have to be worked out during the design. Another complication arises with this type of arrangement 


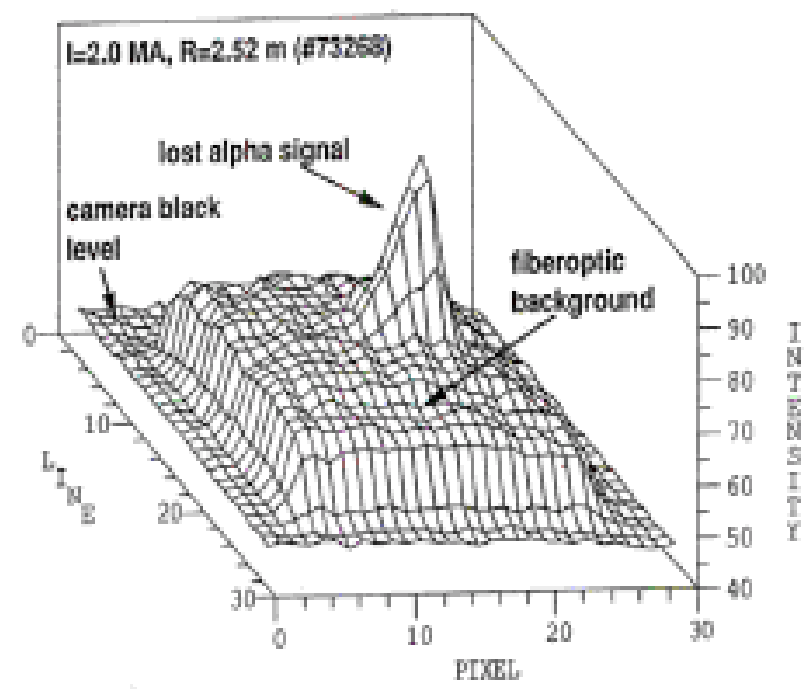

Fig 1. The image of the scintillator in the lost-alpha-particle diagnostic in TFTR showing the pattern of deposition on the $\sim 1 \mathrm{~cm}$ square scintillator. The image is focused onto the end of a coherent quartz fiber bundle. The plateau level of light is fluorescence, possible modified by some absorption, caused by the $14 \mathrm{MeV}$ neutron flux and associated scattered gammas close to the TFTR vacuum vessel.

in that good reflecting surfaces will have to be placed close to the plasma. Sputtering of the reflecting surface by neutral particles from the plasma has been shown to be a concern and it is being investigated for ITER [11].

\section{INTEGRATION ISSUES}

There are four generic issues for diagnostic integration onto FIRE which must be addressed during the design of the tokamak. These are:

i) Developing shield plugs, allowing diagnostic instrument access, for the large radial ports [1]. These plugs have to prevent radiation streaming and so preserve the working environment in the torus hall. Of the sixteen ports only four are presently assigned to heating systems, so that there should be adequate space for the diagnostics.

ii) Diagnostic sightlines into the divertor plasma regions, and views of the divertor contact regions, are required from the upper and lower outer ports. These ports are partially occupied by cooling-water pipes and every second port has vacuum pumps preventing access. There is a gap of $\sim 5 \mathrm{~cm}$ between the divertor plates and the passive tiles which will allow some viewing at the alternate ports. Sightlines across the divertor plasmas will require removal of one column of the tungsten brushes in the divertor to leave a slit $\sim 3 \mathrm{~cm}$ wide.

iii) Space must be made available to fit magnetic field measuring diagnostics between the first wall tiles and the vacuum vessel. The diagnostics consist of some continuous coils both in the toroidal and the poloidal directions and also some small coils for measuring plasma position and magnetic fluctuations. All of these must have cables, probably MI cable, involved in their construction and for connecting them to feedthroughs at ports. The dimensions of these coils will be several tens of millimeters in cross-section to allow for the additional constraints set by RIC, and potential eddy currents in the first-wall components. The dimensions are smaller than on typical devices such as TFTR. Fig. 2 shows the design of the in-vessel hardware at the inside mid-plane location of the FIRE tokamak [1]. While grooving of some material is being studied, the integration of the magnetic diagnostics in this region provides significant challenges.

iv) The understanding of the plasma behavior in tokamaks depends, in large part, on spectroscopic diagnostics, with good spatial distribution, making use of a neutral beam to provide neutral particles near the core of the plasma. These measurements include the ion temperature profile, current density profile, plasma rotation, a technique for studying turbulence, and, for D$\mathrm{T}$ plasmas, helium concentration, profile of slowingdown alpha-particle density and fueling ratios. No alternate methods for providing these key measurements have been found. Hence a neutral beam for diagnostic use is essential. A short pulse, very high-intensity beam $[12]$ is necessary to provide penetration into the highdensity FIRE plasmas without disturbing the plasma. It will require a large penetration at one of the ports.

\section{DiAgNOSTICS FOR ALPHA-PARTICLES}

For plasmas with $\mathrm{Q} \geq 5$, the alpha-particles will dominate the heating of the plasma. They will also provide free energy for driving instabilities. The first physics studies of the alpha-particles and their effects on their host plasma were carried out on TFTR [3], [10]. Some of the effects of alpha-particles on stability can be simulated with fast ions created by RF heating but the definitive program of study is part of the FIRE mission. Hence a full measurement capability for the alpha-particles and associated instabilities is necessary. Unfortunately many diagnostics are needed to fully characterize these particles.

Escaping alpha-particles can be measured by scintillators, as in fig. 1, or Faraday cups [13]. Both techniques need considerable development before being applicable in FIRE. Total energy loss can be obtained by infra-red imaging of the outer wall.

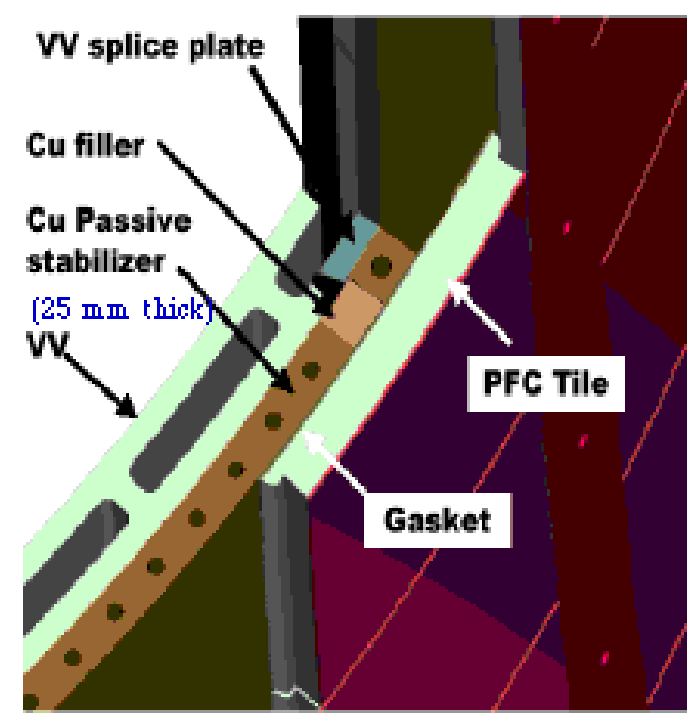

Fig 2. Design of the inner-wall hardware for FIRE showing the plasma-facing tiles and structural and cooling system [1]. No slots are shown for magnetic diagnostics. 
Various techniques have beenapplied for measuring the confined alpha-particles, but these also need major development before application is possible for FIRE.

a) Collective Thomson scattering has been used successfully for studying fast-ion redistribution on TEXTOR using ICRF-heated ions [14]. The high magnetic field and high density of FIRE requires that this scattering should be done in the far-infra-red, a spectral region needing development.

b) Charge exchange spectroscopy measuring the high wavelength tail of a neutral helium spectral line was used on TFTR to measure particles with energy $\leq 700$ $\mathrm{keV}$ [10]. It requires a neutral beam and good background discrimination.

c) Analysis of the neutral helium atoms which have exchanged charge with the dense neutral cloud created by a lithium pellet injected into the plasma [10]. This technique gives resolution in space and energy. Development of penetrating, repetitive pellet injection is needed.

d) Measurement of the high energy tail of the neutron spectra caused by alpha-particles colliding with the fuel ions and accelerating them so that the fusionproduct neutrons are at relatively high energy. Bubble chambers [15] and spectroscopy [16] have been tried for this technique but significant development is required to achieve temporal and spatial resolution.

Very good diagnostics for measurement of turbulence potentially associated with the alpha-particles are essential. Good high-frequency magnetic coils and reflectometry are strong candidate methods.

\section{R\&D REQUIREMENTS}

The rigors of burning plasma experiments lead to requiring a number of technological improvements for plasma diagnostics. These range from developing high reliability for both physics and control reasons to being able to tolerate radiation effects during the burn period. An effective program of R\&D was carried out for ITER [8], but there are still significant needs prior to operation of FIRE. The program will be coordinated with ITER colleagues. Alpha particle diagnostics must be brought to a much more mature level for FIRE than for TFTR. Participation by the U.S. with such diagnostics in the second D-T program on JET must be encouraged.

A key technological development is that of a focused, high-power, short-pulse neutral beam. An $\sim 125 \mathrm{keV} / \mathrm{amu}$ beam at $1 \times 10^{6} \mathrm{Am}^{-2}$ in a cross-section of $0.2 \mathrm{~m} \mathrm{x} 0.2 \mathrm{~m}$ at the plasma edge for $1 \mu \mathrm{sec}$ at $30 \mathrm{~Hz}$ repetition rate would be ideal. A high-speed repetitive impurity pellet injector should also be developed.

Radiation issues are going to be significant and assuring that RIC in insulators is tolerable and other effects such as induced voltages or fluorescence do not preclude measurement is paramount. Mundane developments such as new electrical connector techniques in vacuum for reliability and work with remote-handling tools must be carried out.

\section{SUMMARY AND ACKNOWLEDGMENT}

Over forty different plasma and first wall measurements are considered necessary to carry out the FIRE science program, and so show a clear route toward a fusion reactor. A preliminary layout of the associated diagnostics equipment on the tokamak has been made. Much detailed design work remains to determine whether the equipment can be accommodated while maintaining the device integrity and to show whether instrumental performance can meet the specifications. This paper has shown some of the challenges created by the need to study science on a compact burning plasma device.

The author owes a debt of thanks to Dale Meade and the FIRE team with whom he has been working.

\section{REFERENCES}

[1] D.M. Meade, S.C. Jardin, C.E. Kessel, M.A. Ulrickson, J.H. Schultz, P.H. Rutherford, et al., "Mission and design of the Fusion Ignition Research Experiment (FIRE)," in Proceedings of 18th IAEA Fusion Energy Conference, Sorrento, IAEA, Vienna, 2001, paper IAEA$\mathrm{CN}-77 / \mathrm{OV} / 1$.

[2] M. Keilhacker, A. Gibson, C. Gormezano, P.J. Lomas, P.R. Thomas, M.J. Watkins et al., "High fusion performance from deuteriumtritium plasmas in JET," Nucl. Fusion, vol 39, pp 209 - 234, Feb.1999.

[3] R.J. Hawryluk, "Results from deuterium-tritium tokamak experiments," Rev. Mod. Phys., vol 70, pp 537 - 587, Apr. 1998.

[4] ITER Physics Expert Group on Diagnostics, ITER Physics Basis Editors, "ITER physics basis, chapter 7: Measurement of Plasma Parameters," Nucl. Fusion, vol 39, pp 2541 - 2575, Dec. 1999.

[5] K. Ebisawa, A.E. Costley, A.J.H. Donné, G. Janeschitz, S. Kasai, A. Malaquias, et al., "Plasma diagnostics for ITER-FEAT," Rev. Sci. Instrum., vol 72, pp 545 - 550, Jan. 2001.

[6] M. Ulrickson, "Design of the Fusion Ignition Research Experiment (FIRE) plasma facing components," in Proceedings of 19th IEEE/NPS Symposium on Fusion Engineering, Paper PC-2-14, Jan. 2002.

[7] M. Sawan, Fusion Technology Institute, University of Wisconsin, Madison, WI, personal communication, 2001.

[8] A.E. Costley, D.J. Campbell, S. Kasai, K.M. Young and V. Zaveriaev, "ITER R\&D: auxiliary systems: plasma diagnostics," Fus. Eng. \& Des., Vol. 55, pp 331 - 346, July 2001.

[9] A.T. Ramsey, "D-T radiation effects on TFTR diagnostics," Rev. Sci. Instrum., vol. 66, pp 871 - 876, Jan. 1995.

[10] S.J. Zweben, R.V. Budny, D.S. Darrow, S.S. Medley, R. Nazikian, B.C. Stratton et al., "Alpha particle physics experiments in the Tokamak Fusion Test Reactor," Nucl. Fusion, vol. 40, pp 91 - 149, Jan. 2000.

[11] V. Voitsenya, A.E. Costley, V. Bandourko, A. Bardamid, V. Bondarenko, Y. Hirooka, N. Klassen et al., "Diagnostic first mirrors for burning plasma experiments," Rev. Sci. Instrum., vol 72, pp 475 - 482, Jan. 2001

[12] H.A. Davis, J.C. Olson, W.A. Reass, C.W. Barnes, R.R. Bartsch, D.M. Coates et al., "Progress toward a microsecond duration, repetitively pulsed, intense-ion beam for active spectroscopy measurements on ITER," Rev. Sci. Instrum., vol 68, pp 332 - 335, Jan. 1997.

[13] F.E. Cecil, B. Roy, C. Sutton and N. Wasinger, "A thin film device as a low energy, high flux charged particle spectrometer," Rev. Sci. Instrum., vol 72, pp 792 - 795, Jan. 2001.

[14] H. Bindslev, "Fast ion dynamics by collective Thomson scattering", in Advanced Diagnostics for Magnetic and Inertial Fusion, submitted for publication.

[15] R.K. Fisher, P.B. Parks, J. Liptac, D.C. Ingram, C.E. Brient, S.S. Medley et al., "Measured response of bubble neutron detectors and prospects for alpha knock-on diagnostics," Rev. Sci. Instrum., vol72, pp 796 - 800, Jan. 2000.

[16] J. Källne, L. Ballabio, J. Frenje, S. Conroy, G. Ericsson, M. Tardocchi, E. Traneus and G. Gorini, "Observation of the alpha particle "knock-on" neutron emission in magnetically confined DT fusion plasmas, Phys. Rev. Lett., vol 86, pp 1246 - 1249, Aug. 2000. 


\section{External Distribution}

Plasma Research Laboratory, Australian National University, Australia

Professor I.R. J ones, Flinders University, Australia

Professor J oão Canalle, Instituto de Fisica DEQ/IF - UERJ , Brazil

Mr. Gerson O. Ludwig, Instituto Nacional de Pesquisas, Brazil

Dr. P.H. Sakanaka, Instituto Fisica, Brazil

The Librarian, Culham Laboratory, England

Library, R61, Rutherford Appleton Laboratory, England

Mrs. S.A. Hutchinson, JET Library, England

Professor M.N. Bussac, Ecole Polytechnique, France

Librarian, Max-Planck-Institut für Plasmaphysik, Germany

J olan Moldvai, Reports Library, MTA KFKI-ATKI, Hungary

Dr. P. Kaw, Institute for Plasma Research, India

Ms. P.J . Pathak, Librarian, Insitute for Plasma Research, India

Ms. Clelia De Palo, Associazione EURATOM-ENEA, I taly

Dr. G. Grosso, Instituto di Fisica del Plasma, Italy

Librarian, Naka Fusion Research Establishment, J AERI, J apan

Library, Plasma Physics Laboratory, Kyoto University, J apan

Research Information Center, National Institute for Fusion Science, J apan

Dr. O. Mitarai, Kyushu Tokai University, J apan

Library, Academia Sinica, Institute of Plasma Physics, People's Republic of China

Shih-Tung Tsai, Institute of Physics, Chinese Academy of Sciences, People's Republic of China

Dr. S. Mirnov, TRINITI, Troitsk, Russian Federation, Russia

Dr. V.S. Strelkov, Kurchatov Institute, Russian Federation, Russia

Professor Peter Lukac, Katedra Fyziky Plazmy MFF UK, Mlynska dolina F-2, Komenskeho Univerzita, SK-842 15 Bratislava, Slovakia

Dr. G.S. Lee, Korea Basic Science Institute, South Korea

Mr. Dennis Bruggink, Fusion Library, University of Wisconsin, USA

Institute for Plasma Research, University of Maryland, USA

Librarian, Fusion Energy Division, Oak Ridge National Laboratory, USA

Librarian, Institute of Fusion Studies, University of Texas, USA

Librarian, Magnetic Fusion Program, Lawrence Livermore National Laboratory, USA

Library, General Atomics, USA

Plasma Physics Group, Fusion Energy Research Program, University of California at San Diego, USA

Plasma Physics Library, Columbia University, USA

Alkesh Punjabi, Center for Fusion Research and Training, Hampton University, USA

Dr. W.M. Stacey, Fusion Research Center, Georgia Institute of Technology, USA

Dr. J ohn Willis, U.S. Department of Energy, Office of Fusion Energy Sciences, USA

Mr. Paul H. Wright, Indianapolis, Indiana, USA 
The Princeton Plasma Physics Laboratory is operated by Princeton University under contract with the U.S. Department of Energy.

\author{
Information Services \\ Princeton Plasma Physics Laboratory \\ P.O. Box 451 \\ Princeton, NJ 08543
}

Phone: 609-243-2750

Fax: 609-243-2751

e-mail: pppl_info@pppl.gov

Internet Address: http://www.pppl.gov 